\title{
Consumers mediate natural variation between prey richness and resource use in a benthic marine community
}

\author{
Robin Elahi ${ }^{1,2, *}$, Kenneth P. Sebens ${ }^{1,2,3}$ \\ ${ }^{1}$ Friday Harbor Laboratories, University of Washington, Friday Harbor, Washington 98250, USA \\ ${ }^{2}$ Department of Biology, University of Washington, Seattle, Washington 98195, USA \\ ${ }^{3}$ School of Aquatic and Fisheries Sciences, University of Washington, Seattle, Washington 98195
}

\begin{abstract}
Space is the limiting resource for sessile organisms on marine rocky substrata, and the availability of space is decreased by recruitment and growth but increased through senescence, physical disturbance and consumption. In the present study, we examined whether consumers mediate variation in the relationship between prey richness and resource (space) use in subtidal epifaunal communities. First, we used surveys to identify relationships between prey richness, consumer richness, consumer identity and consumer abundance with available space. As predicted, available space was inversely correlated with sessile prey richness and positively correlated with consumer richness. However, a model selection approach identified the abundance of sea urchins and chitons specifically as the best predictors of available space, suggesting that the proportion of available space is a reasonable indicator of recent disturbance. Next, we manipulated urchin density in the field to test the hypothesis that urchins control the structure of this community by grazing sessile taxa and facilitating smaller consumers. Diet analyses and structural equation models together indicate that urchins generate available space directly by consuming macroscopic sessile prey, and indirectly by facilitating chitons, which maintain patches of space free of microscopic algae and recruits of larger sessile taxa. The significant interaction between prey richness and experimental urchin density on available space suggests that prey richness may buffer the impacts of urchin grazing. More generally, we highlight the need to study the effects of species richness on the structure of communities in the context of relevant ecological processes.
\end{abstract}

KEY WORDS: Space $\cdot$ Diversity $\cdot$ Strongylocentrotus $\cdot$ Tonicella $\cdot$ Subtidal $\cdot$ Epifauna

Resale or republication not permitted without written consent of the publisher

\section{INTRODUCTION}

Although ecologists have long investigated the causes of species richness (MacArthur \& Wilson 1963, Connell 1978), more recently the focus has shifted to the consequences of richness within an ecosystem function framework (Hooper et al. 2005, Stachowicz et al. 2007). An accumulating body of experiments has demonstrated a positive effect of genotypic, species and functional diversity on various ecosystem functions, including productivity, biomass, resource use and resistance to environmental perturbations (Balvanera et al. 2006). However, the effect of diversity inferred from a carefully controlled experiment may be overwhelmed by other processes (Grace et al. 2007), such as propagule supply (Levine 2000) and disturbance (Cardinale et al. 2005). Consequently, researchers are now examining the effects of biodiversity change in the field (Stachowicz et al. 2008, Spooner \& Vaughn 2009), and in the context of environmental factors known to affect the structure and function of communities (e.g. herbivory; Parker et al. 2010, Bracken et al. 2011). 
In particular, interpreting the consequences of richness within a trophic context is imperative to conservation because species are being lost at upper trophic levels through extinctions, but gained at lower trophic levels through introductions (Byrnes et al. 2007). The manipulation of consumer abundance and/or diversity has revealed strong top-down control in some marine and terrestrial systems, which can ultimately impact ecosystem function (Paine 2002). In marine communities the effects of mobile consumers are ubiquitous (Connell 1961, Paine 1966, Lubchenco 1978, Underwood et al. 1983) and operate to restart succession through the provision of available space. Space on primary substrata is considered to be the limiting resource for sessile algae and filterfeeding invertebrates in rocky intertidal (Dayton 1971) and subtidal habitats (Sebens 1986a, Vance 1988). Fluctuations in available space are buffered by greater numbers of sessile species, leading to increased stability and reduced invasibility in experimental marine communities (Stachowicz et al. 2002).

Hard-bottom marine communities are tractable systems in which to test the relative importance of grazing and richness on resource use because the resource - available space - is easily quantified as a percentage of total space cover. We focused on epifaunal communities on subtidal vertical rock surfaces (walls) because they harbor an impressive diversity of sessile taxa that occupy the relatively 2-dimensional and homogeneous space (Witman et al. 2004, Miller \& Etter 2011). Importantly, subtidal rock walls are exposed to minimal physical disturbance, unlike more commonly studied rocky intertidal shores or shallow subtidal reefs (Witman \& Dayton 2001). Consequently, the dynamics of space occupation are determined primarily by the recruitment and growth of sessile taxa and counteracted by their death, caused primarily by intrinsic factors, competition or predation. In particular, grazing by a variety of generalist and specialist consumers, including mollusks, crustaceans and echinoderms, provides newly available space (Sebens 1986b, Miller \& Etter 2011).

Classic field experiments have highlighted the effects of consumer identity (Paine 1992) and density (Underwood et al. 1983). More recent studies testing the role of consumer richness have also found strong support for the role of particular species (Duffy et al. 2001, Duffy et al. 2003, Byrnes \& Stachowicz 2009). Urchins and chitons are 2 well-studied but morphologically dissimilar consumers, each of which can exert strong effects in hard-bottom marine communities. In the San Juan Islands, Washington, USA, red urchins Strongylocentrotus franciscanus and lined chitons
Tonicella spp. are conspicuous on subtidal rock walls. Red urchins attain large sizes (test diameter $>18 \mathrm{~cm}$ ) and eat primarily kelp (Vadas 1977, Britton-Simmons et al. 2009), but will feed opportunistically on invertebrates (Duggins 1981, Epelbaum et al. 2009). Notably, their removal does not lead to changes in kelp communities (Carter et al. 2007) observed in similar experiments on shallow reefs elsewhere (Duggins 1980). It is likely that these urchins do not graze heavily upon attached algal thalli, but capture drift kelp transported by strong tidal currents (Britton-Simmons et al. 2009). In comparison, lined chitons are small $(<3 \mathrm{~cm})$ and feed on crustose coralline algae (Demopulos 1975) and diatoms (Latyshev et al. 2004). However, the ecological effects of these 2 consumers on invertebrate-dominated vertical rock surfaces are unknown, and are likely to differ from those on algal-dominated horizontal rocky substrata.

The primary goal of this study was to examine how grazing pressure influences the relationship between sessile prey richness and space availability on subtidal rock walls. With respect to grazing, we evaluated the role of consumer richness, consumer identity and consumer density. Using field surveys, we first identified urchins and chitons as potentially 'strong' interactors in this community from a suite of diverse consumers (e.g. molluscs, arthropods and echinoderms) based on their abundances and known categories of prey. Then we examined relationships between sessile prey richness, mobile consumer richness, urchin and chiton densities, and available (cleared) space. We hypothesized that the percent cover of available space would relate inversely with prey richness (Stachowicz et al. 1999) but positively with consumer richness and density (Byrnes \& Stachowicz 2009). A field experiment tested the role of urchins in creating the observed patterns from our surveys, and changes in the relative abundances of sessile taxa were compared with the gut contents of urchins and chitons. Finally, we used structural equation modeling (Grace et al. 2010) to test the hypothesis that urchins exert indirect effects on space availability by facilitating chiton grazing.

\section{MATERIALS AND METHODS}

\section{Field surveys}

We established a hierarchical sampling design of permanent quadrats on subtidal rock walls at 3 sites with the explicit goal of relating spatial variation in 
diversity and resource availability of the sessile prey community to the abundance of mobile consumers. The sites, Shady Cove (San Juan Island; $48^{\circ} 33^{\prime} 8^{\prime \prime} \mathrm{N}$, $123^{\circ} 0^{\prime} 20^{\prime \prime} \mathrm{W}$ ), Point George (Shaw Island; $48^{\circ} 33^{\prime} 33^{\prime \prime} \mathrm{N}$, $122^{\circ} 59^{\prime} 18^{\prime \prime} \mathrm{W}$ ) and $\mathrm{O}^{\prime} \mathrm{Neal}$ (O'Neal Island; $48^{\circ} 36^{\prime} 17^{\prime \prime} \mathrm{N}$, $\left.123^{\circ} 5^{\prime} 34^{\prime \prime} \mathrm{W}\right)$, are $2-8 \mathrm{~km}$ apart within San Juan Channel, Washington, USA. They are characterized by steep walls ranging in size from 2 to $10 \mathrm{~m}$ in height, interspersed with horizontal and sloping rock substrata.

In December 2007, permanent horizontal transects ( $2.5 \mathrm{~m}$ long, $\mathrm{n}=6$ ) separated by at least $5 \mathrm{~m}$ were installed haphazardly on rock walls between 12 and $18 \mathrm{~m}$ depth at each site. Quadrats $\left(0.09 \mathrm{~m}^{2}, \mathrm{n}=4\right)$ were positioned randomly along transects with corners marked with marine epoxy to enable repeated sampling of the benthos. Photographs of quadrats were taken using an Olympus C-8080 digital camera with an Ikelite strobe attached to a $36 \times 25 \mathrm{~cm}$ aluminum frame, allowing identification of organisms $\geq 3 \mathrm{~mm}$ in diameter. These photographs were used to quantify percent cover of sessile taxa, as well as the densities of chitons and other 'small' $(<3 \mathrm{~cm}$ adult size) consumers. Concurrently, the abundance of 'large' ( $>3 \mathrm{~cm}$ adult size) consumers was quantified within $1 \mathrm{~m}$ above and below each transect. In this paper we describe patterns of sessile prey richness and space availability from photographs taken in July 2008. Because of their high mobility, consumer densities in quadrats and on transects were estimated over 3 time points: December 2007, March 2008 and July 2008. Consumers were defined as those mobile macro-invertebrates capable of scraping invertebrates or algae off rock surfaces, or able to consume whole or parts of sessile organisms such that space is made available for recruitment. Occupied space is generally not available for recruitment, but may be available to certain competitively superior species by direct overgrowth (Sebens 1986a).

\section{Field experiment}

We conducted a field experiment to test hypotheses related to the effects of the red urchin Strongylocentrotus franciscanus (hereafter 'urchin') on the benthic community. Specifically, we were interested in the effect of urchins on space availability, prey richness, consumer richness and the density of lined chitons Tonicella spp. (hereafter 'chitons'). Approximately 20 urchins ( 4 urchins $\mathrm{m}^{-2}$ ) were added to 3 new permanent transects $(2.5 \mathrm{~m})$ on rock walls
(12-18 m depth) at each site. At Shady Cove, one transect was interspersed within the original permanent transects, and one was placed at either end. At O'Neal and Point George, 2 transects were placed at one end, and the third at the other end of the original transects. The experimental target density of urchins was within the natural range of densities (05.2 urchins $\mathrm{m}^{-2}$ ) observed during monitoring dives. These experimental transects (hereafter 'addition' transects) were compared with 3 transects without the addition of urchins (hereafter 'control' transects) from the permanent monitoring study (see above), using a before-after, control-impact design. Ten to 12 photographs were taken within $1 \mathrm{~m}$ of each transect immediately before the addition of urchins (27 June 2009) and at the end of the experiment (24 September 2009). Six photographs from each transect were selected randomly for the analysis of mobile and sessile species richness and cover (see below). Approximately every 2 wk (6 observations during the experiment), we quantified the density of urchins on all transects, and added urchins as necessary to maintain the target density on addition transects. Urchin collections were focused $\sim 3 \mathrm{~m}$ above and below target transects, and care was taken to ensure that urchins were not collected from the vicinity of neighboring transects.

\section{Urchin and chiton diets}

To determine whether the diets of the 2 major consumers reflected our field observations of prey removal, we quantified the gut contents of urchins and chitons from the rock wall communities. Urchins $(\mathrm{n}=36)$ and chitons $(\mathrm{n}=29)$ were collected for gut content analysis from permanent monitoring transects at O'Neal, Point George and Shady Cove in April 2009. All consumers were taken to the University of Washington's Friday Harbor Laboratories for dissection, and gut contents were isolated and frozen $\left(-20^{\circ} \mathrm{C}\right)$ for subsequent analysis. For urchin gut contents, we used a protocol modified from Cobb \& Lawrence (2005) to estimate the proportions of several food categories. After thawing, urchin samples were mixed thoroughly and a representative layer of contents was spread evenly into a Petri dish. Contents were viewed using a dissecting scope $(\times 10$ magnification $)$, and the proportion of prey was estimated from 50 random points. A $6 \times 6 \mathrm{~mm}$ grid was placed under the dish, and food items at 10 random intersections within each of 5 haphazard fields of view were identified to the lowest possible taxo- 
nomic level. Rare taxa viewed in scans of the entire Petri dish were assigned arbitrary values of $0.5 \%$.

The diet of chitons was also quantified visually (Demopulos 1975, Fulton 1975, Robb 1975, Latyshev et al. 2004). In summary, we extracted the contents from the chiton foregut onto a glass slide, and observed them using a compound microscope $(\times 200$ magnification). We used a point count method using 10 equally spaced points on the ocular micrometer for 10 haphazard fields of view (100 points per chiton). Food items were classified into the following categories: microalgae, diatoms, crustose red algae, multicellular algae (filamentous and foliose) and other (unidentified materials and animal parts).

\section{Analysis}

The percent cover of sessile organisms was quantified from photographs using a visual-based method (Dethier et al. 1993). A grid of 20 rectangles was superimposed onto each image and the percent cover of sessile taxa was scored for each rectangle as follows: $0=$ absence, $1=<1 \%, 2=10 \%(1-19 \%)$, $3=30 \%(20-39 \%), 4=50 \%(40-59 \%), 5=70 \%$ $(60-79 \%), 6=90 \%(80-99 \%)$ and $7>99 \%$. The sum of scores for each organism was expressed as a percentage of the total sum for the quadrat. Taxa were scored only if they were attached to rock or encrusting algae. Epibiotic taxa were not quantified because they do not occupy primary space and because habitat-forming 'foundation' species that might facilitate secondary space holders (Stachowicz \& Byrnes 2006) were rare at the study sites. Organisms were identified to the lowest possible taxonomic level and were assigned unique pseuodonyms when species identification was not possible.

We defined available space as the substratum available for the recruitment and growth of macroalgae and sessile invertebrates (Dayton 1971), including bare rock, calcified encrusting algae and non-calcified encrusting algae (as in Sebens 1986b). Encrusting algae are included in the definition of space because there is very little bare rock in shallow hard-bottom subtidal habitats, and most invertebrates can settle on or overgrow coralline and noncalcified algal crusts (Sebens 1986a). In so doing we assumed that these algal crusts are functionally equivalent, in part for simplicity, but also because the extent to which various species of encrusting algae facilitate (Morse et al. 1988) or inhibit (Breitburg 1984) the settlement of other sessile taxa is poorly understood in this community. Because we consid- ered encrusting algae to be available space, we did not include them in our estimates of richness and diversity.

We used a linear mixed-effects model and Akaike's information criterion corrected for small sample size $\left(\mathrm{AIC}_{\mathrm{c}}\right.$ ) to infer the best model (Burnham \& Anderson 2002) predicting the percent cover of available space (logit transformed). For the surveys completed in 2008, we tested the relative importance of sessile prey richness, consumer richness, density of red urchins and density of chitons. These 2 morphologically dissimilar consumers were selected because only their densities exhibited significant positive relationships to available space (Table S1 in the Supplement at www.int-res.com/articles/suppl/m452 p131_supp.pdf), and because they were relatively abundant at the study sites (Fig. S1 in the Supplement). Transect was nested within site and both were treated as random effects; quadrats were treated as the unit of replication.

To determine whether urchin abundance was related causally to the patterns of the other independent predictors of available space in the 2008 surveys, we tested the fixed effects of experimental treatment (control and urchin addition) on changes in sessile functional groups (percent cover), prey richness, prey evenness, consumer richness and chiton density (no. $\mathrm{m}^{-2}$ ) over the 3 mo experiment. We calculated the mean of each dependent variable for each transect ( $\mathrm{n}=6$ quadrats) at the beginning and end of the 3 mo experiment. We then used a linear mixed-effects model to test for change in dependent variables. Site was treated as a random effect; transects were treated as the unit of replication.

To test whether urchins change the relationship between available space and prey richness, we capitalized on variation in the manipulated urchin densities during the course of the 2009 experiment. Urchins were not restricted in their movement to or from transects, resulting in some overlap in densities between treatments, especially at O'Neal (Table S2 in the Supplement). Therefore, we treated the mean density of urchins (per transect) as a continuous variable, and used a linear mixed-effects model to test the effects of urchin density, prey richness (in quadrats at the end of the experiment) and their interaction on available space in quadrats at the end of the experiment. Transect was nested within site and both were treated as random effects; quadrats were treated as the unit of replication. The mean density of urchins was calculated from the number of urchins remaining on transects 2 wk after every urchin addition (Table S2 in the Supplement). There- 
fore, our estimates of mean urchin density throughout the manuscript can be considered conservative.

For all of our linear mixed-effects models, we used a Monte Carlo Markov chain resampling method to test the significance of fixed effects because the number of degrees of freedom in the denominator of a linear mixed-effects model is uncertain (Baayen et al. 2008). Residuals were inspected visually for normality and homoscedasticity. Note that because of the limitation of species identification from high-resolution quadrat photographs, both prey richness and consumer richness include categories that comprise not only species, but also higher taxa, which comprise several species. We consider this limitation to be acceptable, because the same categories were used across surveys and experiments.

Quantile regression was used to illustrate the relationships between available space and its predictors (sessile prey richness, consumer richness, chiton density and urchin density), because we were interested in testing the upper and lower limits of the response variable distribution (Cade \& Noon 2003), not just the mean response. Furthermore, some of the bivariate distributions (e.g. space vs. prey richness) violated the assumption of homoscedasticity for ordinary least squares regression (Cade \& Noon 2003), and the quantile approach provided a uniform testing approach for all regressions. For the survey data (2008), we calculated the 15th and 85th quantiles ( $\tau=0.15$ and 0.85 , respectively) to estimate the upper and lower bounds to the relationship between available space and the independent variables, as well as median quantiles $(\tau=0.5)$ across all 3 sites. For data collected at the end of the experiment (September 2009), we calculated median quantiles for 3 ranges of urchin densities (0-0.2, 0.2-1.2 and 1.2-4.4 urchins $\mathrm{m}^{-2} ; \mathrm{n}=36$ for each range), but included all quadrats to estimate 10th and 90th quantiles ( $\tau=0.1$ and 0.9 , respectively). We used slightly more extreme quantiles because of the increased sample size ( $\mathrm{n}=108$ as opposed to $\mathrm{n}=72$ ) for the regressions ( $\mathrm{n}>10 \tau_{\tau_{\text {lower }}}$ Scharf et al. 1998). Lastly, to investigate potential mechanisms driving variation between available space and prey richness, we calculated median quantile regressions between the percent cover of macroalgae and clonal ascidians (both response variables) as a function of prey richness (predictor) before and after the addition of urchins to experimental transects ( $\mathrm{n}=54$ for each time point). Statistical analyses were conducted using the packages lme4 (Bates et al. 2011) and quantreg (Koenker 2011) in R 2.13 (R Development Core Team 2011).

\section{Structural equation modeling}

The analysis of our observational and experimental data, together with the literature on the effects of consumers on sessile prey in marine systems, led to the development of structural equation models (StEMs; Grace et al. 2010). The use of StEMs allowed us to distinguish between alternative hypotheses representing the direct (i.e. consumption of sessile prey) and indirect effects of urchin grazing (i.e. facilitation of chitons) on benthic community structure. We did not include consumer richness in our StEMs for simplicity, and because it was highly correlated with chiton density ( $\mathrm{r}>0.71$ ) in both datasets.

The saturated model, StEM A, represented the direct effects of urchin and chiton grazing on the sessile community, as well as the indirect effects of urchins mediated through chiton grazing. We included a path from urchin density to available space and prey richness because urchin grazing clears space and affects prey richness (Paine \& Vadas 1969, Sebens 1986b). A path from urchin density to chiton density represented facilitation (Dethier \& Duggins 1984) by urchins. Paths from chiton density to prey richness and available space represented the direct effect of chiton grazing on sessile prey (Duggins \& Dethier 1985, Paine 1992). We included a covariance term between prey richness and available space because it is uncertain which variable is causal, and because both are likely to be affected by consumers simultaneously.

In StEM B, both urchins and chitons exert direct effects on the sessile community through grazing, but urchins do not facilitate chitons. This model was identical to StEM A, except that it lacked the path from urchin density to chiton density. In StEM C, urchins exert direct effects on sessile taxa and facilitate chitons, but chitons do not exert measurable effects on the sessile community. This model was identical to StEM A, except that it lacked the paths from chiton density to prey richness and available space. In StEM D, urchins (but not chitons) exert direct effects on the sessile community, and do not facilitate chitons. This last model was identical to StEM A, but lacked paths from urchin density to chiton density, as well as paths from chiton density to prey richness and available space. In all StEMs, urchin and chiton density were $\log (x+1)$-transformed and available space was logittransformed to improve normality. Nevertheless, the data failed to meet the assumption of multivariate normality; therefore, we used maximum likelihood estimation with robust standard errors and a SatorraBentler scaled test statistic to calculate the fit of our 
models. We used a model selection approach $\left(\mathrm{AIC}_{\mathrm{c}}\right)$ to identify the best model for the survey and experimental data separately. The best-fit model was then used in a multi-group analysis (Grace \& Pugesek 1998) to test whether the magnitude and direction of the causal paths differed between the survey and experimental data. All analyses were conducted using the lavaan package (Rosseel et al. 2011) in R.

\section{RESULTS}

In surveys (2008) across the 3 sites, available space was correlated negatively with sessile prey richness and positively with consumer richness, chiton density and urchin density (Fig. 1). Quantile regression revealed upper and lower limits to the amount of available space as a function of consumer richness, chiton density and urchin density (Fig. 1, Table S3 in the Supplement). In contrast, there was an upper, but not lower, limit to the amount of available space as a function of sessile richness, resulting in a triangular relationship. Of these 4 variables, chiton density was the best single predictor of space (Table 1). The 2 best predictors of space were chiton density and urchin density, a model considerably better than the full model including all 4 predictors $(\Delta i=$ 10.45; Table 1).

During the field experiment (2009), the urchin addition treatment effectively increased the density of urchins relative to the control treatment $(2.3 \pm$ 1.5 vs. $0.3 \pm 0.3$ urchins $\mathrm{m}^{-2}$, mean \pm $1 \mathrm{SD} ; \mathrm{n}=9$ transects per treatment), despite the fact that urchins were free to move. Consequently, urchin grazing on addition transects caused a significant increase in available space (bare rock and encrusting algae), consumer richness and chiton density (Fig. 2, Table S4 in the Supplement). Urchin addition did not significantly affect prey richness, but control transects gained an average of 2 species per quadrat by the end of the experiment (Fig. 2B, Table S4 in the Supplement). The magnitude of the grazing effect on available space was contingent upon the number of sessile species within quadrats, indicated by the urchin density $\times$ prey richness inter-
Table 1. Linear mixed-effects models used to predict percent cover of available space (logit-transformed) in permanent quadrats surveyed in 2008. Transect was nested within site; both were treated as random effects. Candidate models are listed with the number of parameters $(K)$, corrected AIC $\left(\mathrm{AIC}_{\mathrm{c}}\right)$, the difference in AIC between the candidate model and the best model $(\Delta i)$, and Akaike weights $\left(w_{\mathrm{i}}\right)$. The best model, including only the densities of lined chitons Tonicella spp. and red urchins Strongylocentrotus franciscanus, is shown in bold

\begin{tabular}{|lccrc|}
\hline Model & $K$ & $\mathrm{AIC}_{\mathrm{c}}$ & \multicolumn{1}{c|}{$\Delta i$} & $W_{\mathrm{i}}$ \\
\hline Prey richness (PR) & 5 & 247.66 & 35.03 & 0.0000 \\
Grazer richness (CR) & 5 & 234.93 & 22.30 & 0.0000 \\
Chiton density (CD) & 5 & 215.50 & 2.88 & 0.1772 \\
Urchin density (UD) & 5 & 235.27 & 22.65 & 0.0000 \\
PR + CR & 6 & 237.45 & 24.82 & 0.0000 \\
PR + CD & 6 & 221.94 & 9.31 & 0.0071 \\
PR + UD & 6 & 238.48 & 25.85 & 0.0000 \\
CR + CD & 6 & 217.52 & 4.89 & 0.0647 \\
CR + UD & 6 & 231.60 & 18.98 & 0.0001 \\
CD + UD & $\mathbf{6}$ & $\mathbf{2 1 2 . 6 3}$ & $\mathbf{0}$ & $\mathbf{0 . 7 4 6 9}$ \\
PR + CR + CD + UD & 8 & 223.08 & 10.45 & 0.0040 \\
& & & & \\
\hline
\end{tabular}
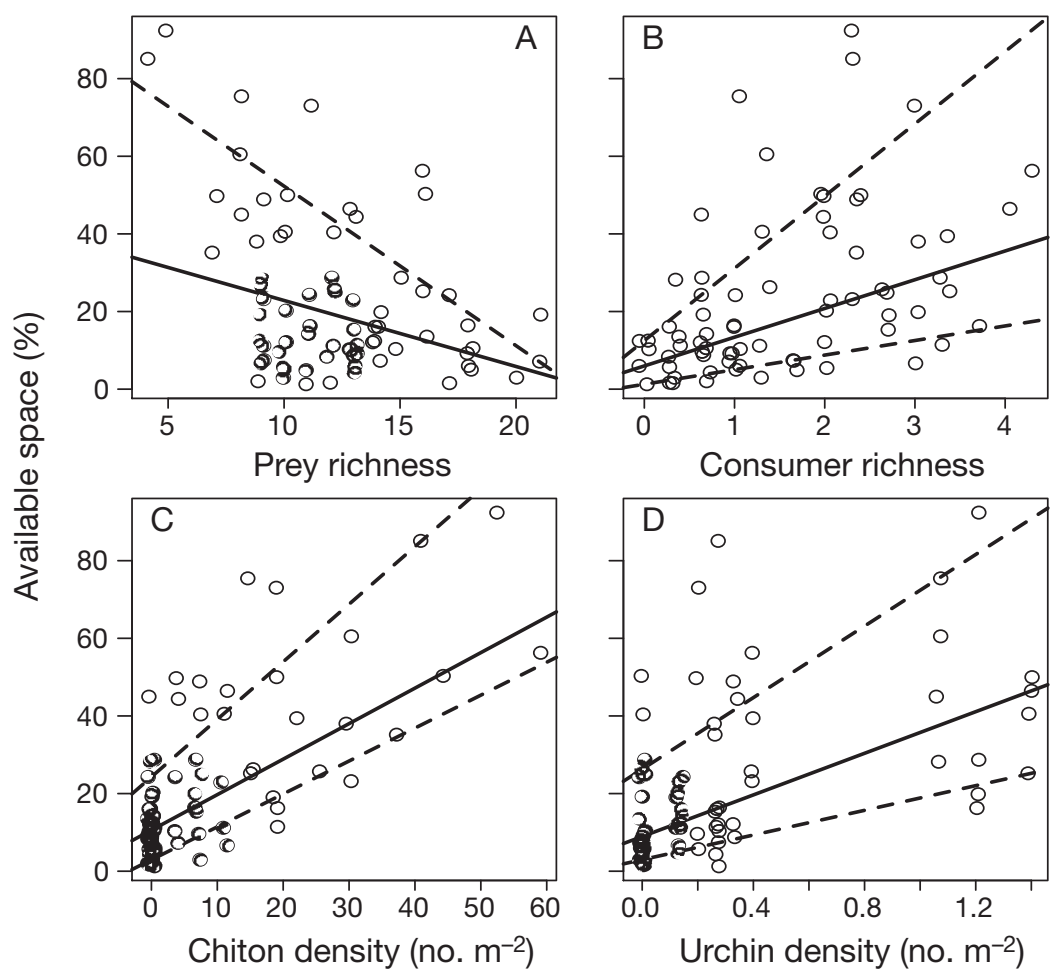

Fig. 1. Percent cover of available space in quadrats plotted as a function of (A) richness of sessile prey taxa in quadrats, (B) richness of consumer taxa in quadrats, (C) density of the lined chiton Tonicella spp. in quadrats, and (D) density of the red urchin Strongylocentrotus franciscanus in transects surveyed in 2008. Black lines show the median (50th quantile) relationship between space and the independent variable, and dashed lines show the upper and/or lower bounds (85th and 15th quantile, respectively) of the relationship when significant $(p<0.05)$. Note the lack of a lower limit to space only when plotted against prey richness (A) 

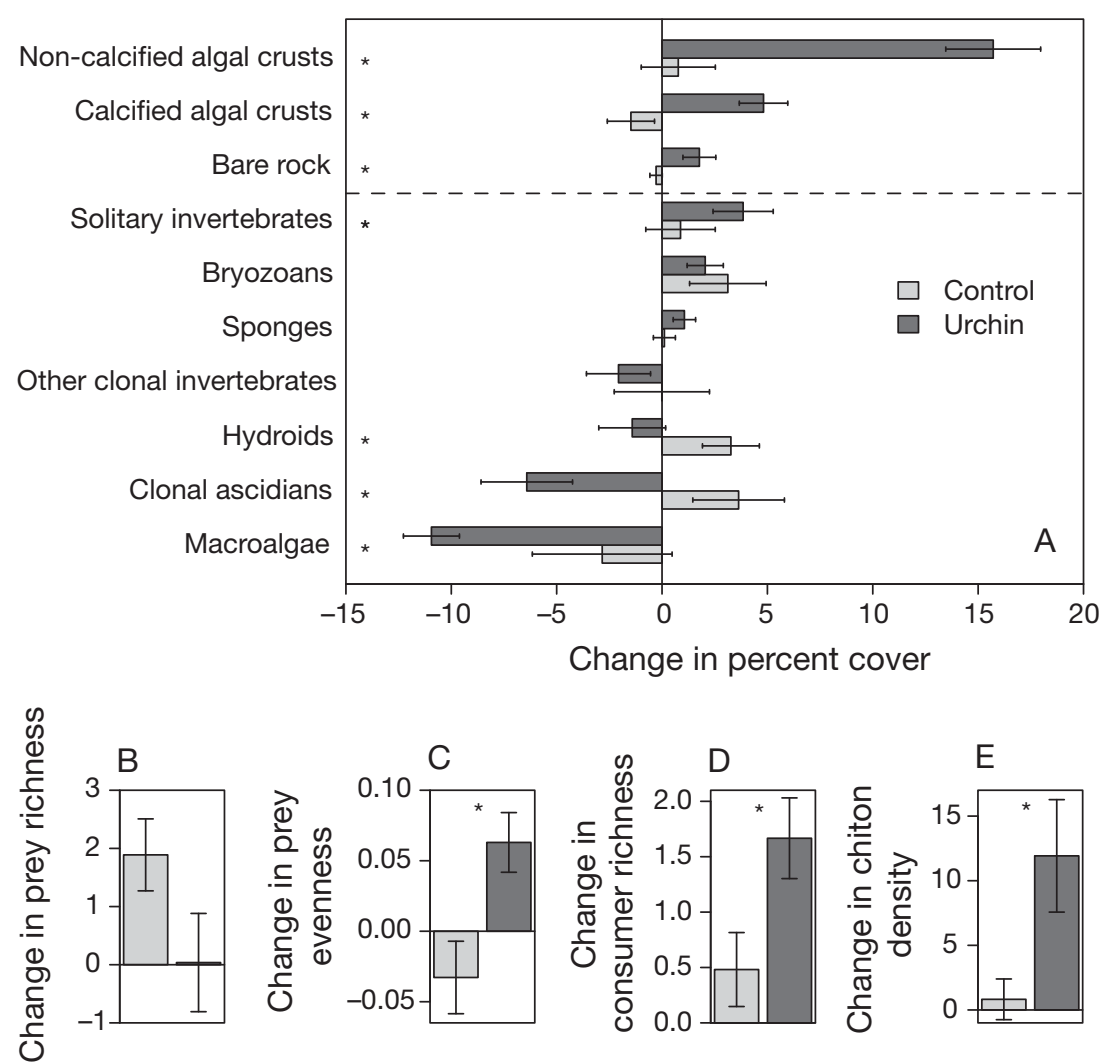

Treatment

Fig. 2. Change in mean $( \pm 1 \mathrm{SE})$ percent cover of $(\mathrm{A})$ functional groups, $(\mathrm{B})$ prey richness, (C) prey evenness, (D) consumer richness and (E) lined chiton density $\left(\right.$ no. $\left.\mathrm{m}^{-2}\right)$ on transects $(\mathrm{n}=9)$ in control and urchin addition treatments from June to September 2009 (pre and post-treatment, respectively). In (A), the 3 functional groups above the dashed line together represent available space. Asterisks denote the significance of a treatment effect in linear mixedeffects models

action (Table S5 in the Supplement). Notably, at the end of the experiment, the median regression between available space and prey richness was significant for quadrats exposed to intermediate and high urchin densities, but not low urchin densities (Fig. 3, Table S3 in the Supplement). In support of the triangular relationship observed in the survey results, there was an upper limit (i.e. the 90th quantile) to available space as a declining function of richness, but no lower limit (Fig. 3, Table S3 in the Supplement).

Urchin grazing caused changes in the relative abundances of sessile taxa by September 2009, the end of the field experiment. After urchin addition, the percent cover of macroalgae (primarily red algae) and clonal ascidians decreased significantly, uncovering bare rock and algal crusts (Fig. 2, Table S4 in the Supplement). Solitary invertebrates, which occupied very little space $(8.3 \pm 5.1 \%$ cover, mean $\pm \mathrm{SD}$, $\mathrm{n}=108)$ relative to clonal invertebrates $(41.1 \pm 17.5 \%$ cover, mean $\pm \mathrm{SD}, \mathrm{n}=108)$ and macroalgae $(14.5 \pm 10.7 \%$ cover, mean $\pm \mathrm{SD}$, $\mathrm{n}=108$ ) in June 2009, actually increased in response to urchin grazing (Fig. 2, Table S4 in the Supplement). In contrast, hydroid cover increased on control transects (Fig. 2, Table S4 in the Supplement). The decline of the spatially dominant sessile taxa (algae and clonal ascidians) on urchin transects corresponded with an increase in prey evenness (Fig. 2C). After the addition of urchins to experimental transects, the percent cover of clonal ascidians became positively correlated with prey richness, but the percent cover of macroalgae remained uncorrelated with prey richness (Fig. 4, Table S3 in the Supplement). The observed reduction in macroalgae and clonal ascidians in the field experiment was consistent with the 2 most abundant prey found in urchin guts (Fig. 5A). Second to algae, the most abundant food item found in urchins was the clonal ascidian Metandrocarpa taylori (Fig. 5A), which was also the most abundant sessile invertebrate species across the 3 study sites before urchin addition $(8.5 \pm 7.6 \%$ cover, mean $\pm \mathrm{SD}, \mathrm{n}=108$ ). In contrast, chitons cannot eat macroalgae and ascidians because of their smaller size, and thus their diet is composed primarily of microalgae and diatoms (Fig. 5B), which are ubiquitous on encrusting algae and 'bare' rock.

The saturated structural equation model (StEM A) best fit the observed data for the survey and experiment (Table 2). The unsaturated StEMs lacking the facilitation of chitons by urchins, and/or chiton grazing, did not fit the observed covariance matrices $(\mathrm{p}<$ 0.01 ; Table 2), and were far worse than StEM A ( $\Delta i>$ 14). Therefore, we used StEM A in a multi-group context (Grace \& Pugesek 1998) to test whether the magnitude and direction of causal paths were consistent between the survey and experimental data. We constructed a model identical to StEM A, but constrained the path coefficients to be identical for both datasets. We focused on the results of the constrained multi-group model because it fit the data nearly as well as StEM A without constraints $(\Delta i=1.4)$ and it adequately reproduced the observed covariance matrix $\left(\chi^{2}=7.6, \mathrm{df}=5, \mathrm{p}=0.18\right)$; we were able to test 


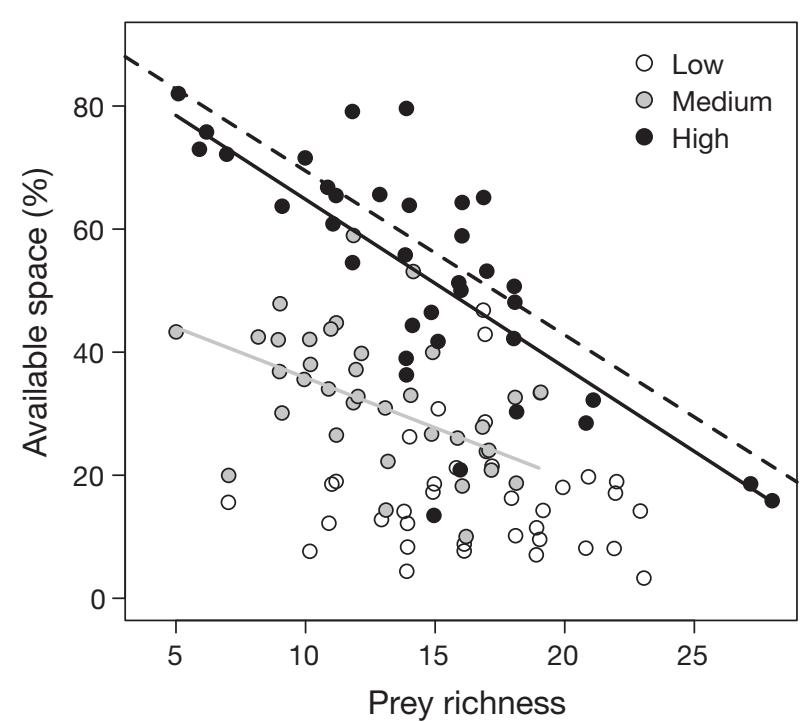

Fig. 3. Available space declines with increasing richness, but only in the presence of red urchin Strongylocentrotus franciscanus grazing at the end of the 2009 experiment. Points represent quadrats subjected to low (0-0.2 urchins $\mathrm{m}^{-2}$; open symbols), medium (0.2-1.2 urchins $\mathrm{m}^{-2}$; grey symbols) and high (1.2-4.4 urchins $\mathrm{m}^{-2}$; black symbols) urchin densities ( $n=36$ quadrats per density). Solid lines depict the median (50th quantile) regression for each urchin density, where significant $(\mathrm{p}<0.05)$. The dashed line represents the upper bound (90th quantile) to space as a function of richness for all quadrats combined. Note that there is no lower limit to space (10th quantile), and no relationship between space and richness at low urchin densities, resulting in a triangular relationship between space and richness

the fit of the constrained model because the equality constraints across the survey and experimental data produced 5 degrees of freedom. R scripts for the 4 StEMs, as well as covariance matrices and means for the survey, experimental and multi-group analyses are provided in Tables S6 \& S7 in the supplement.

All of the hypothesized causal paths in the multigroup, constrained StEM were statistically significant $(p<0.05)$, although there was considerable variation in the magnitude of the path coefficients. The StEM explained variation in available space $\left(\mathrm{R}^{2}=\right.$ $0.46-0.64)$ better than the variation in prey richness $\left(\mathrm{R}^{2}=0.06-0.11\right)$, and the direct effects of consumer densities were stronger on available space than prey richness (Fig. 6). The magnitude of indirect effects is calculated as the product of standardized regression coefficients. With respect to available space, urchins exerted a stronger direct effect $(0.35-0.58)$ relative to the indirect effect $(0.10-0.17)$ mediated via chiton density. Similarly, urchins exerted a stronger direct effect $(\sim-0.15)$ on prey richness relative to the indirect effect $(\sim-0.05)$ mediated via chiton density. We
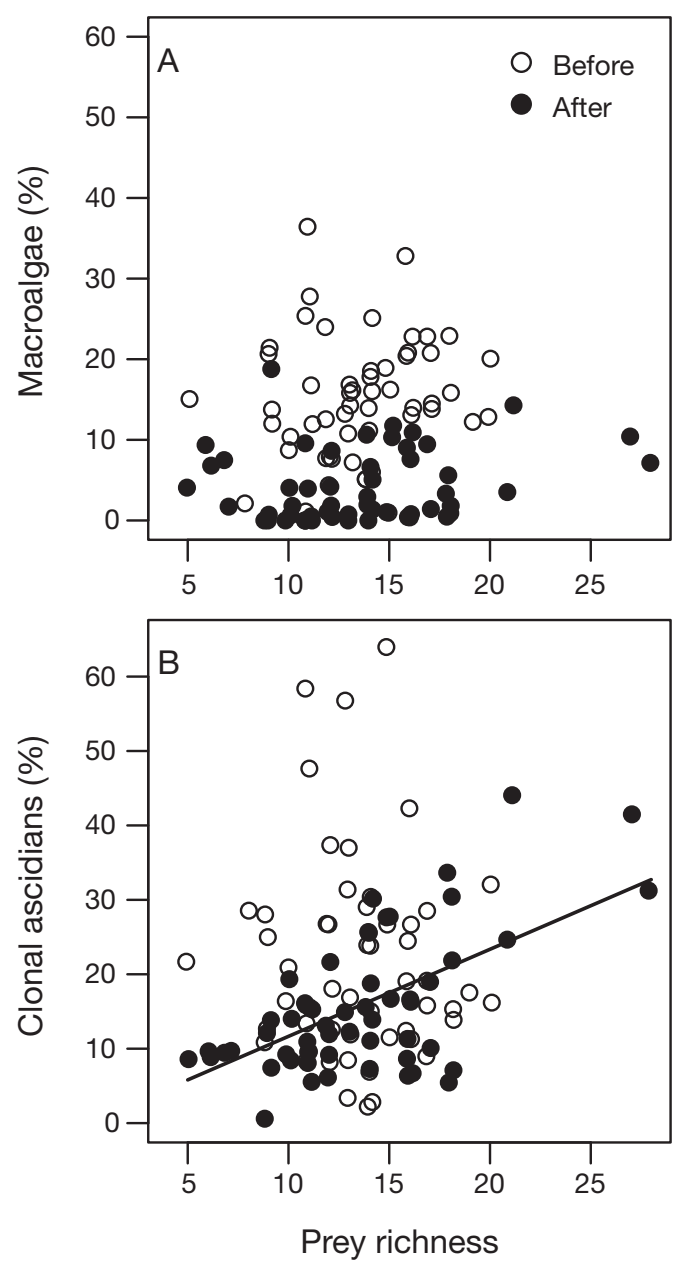

Fig. 4. (A) Percent cover of macroalgae is not related to prey richness, but (B) percent cover of clonal ascidians increases with prey richness after the addition of red urchins Strongylocentrotus franciscanus. Points represent quadrats from urchin transects, before (open circles) and after (filled circles) the addition of urchins during the 2009 experiment. The line represents a significant $(p<0.05)$ median regression

did not constrain the covariation between prey richness and available space, and we observed significant residual covariance between these endogenous variables in the experimental dataset only.

\section{DISCUSSION}

In this study, we demonstrate that natural variation between the number of sessile prey species and resource use on subtidal rock walls is a function of urchin grazing. Urchins mediate this relationship directly by altering the relative abundances of sessile taxa (Fig. 2A), and indirectly by facilitating chitons and their grazing activities (Figs. 2D \& 6). The mech- 

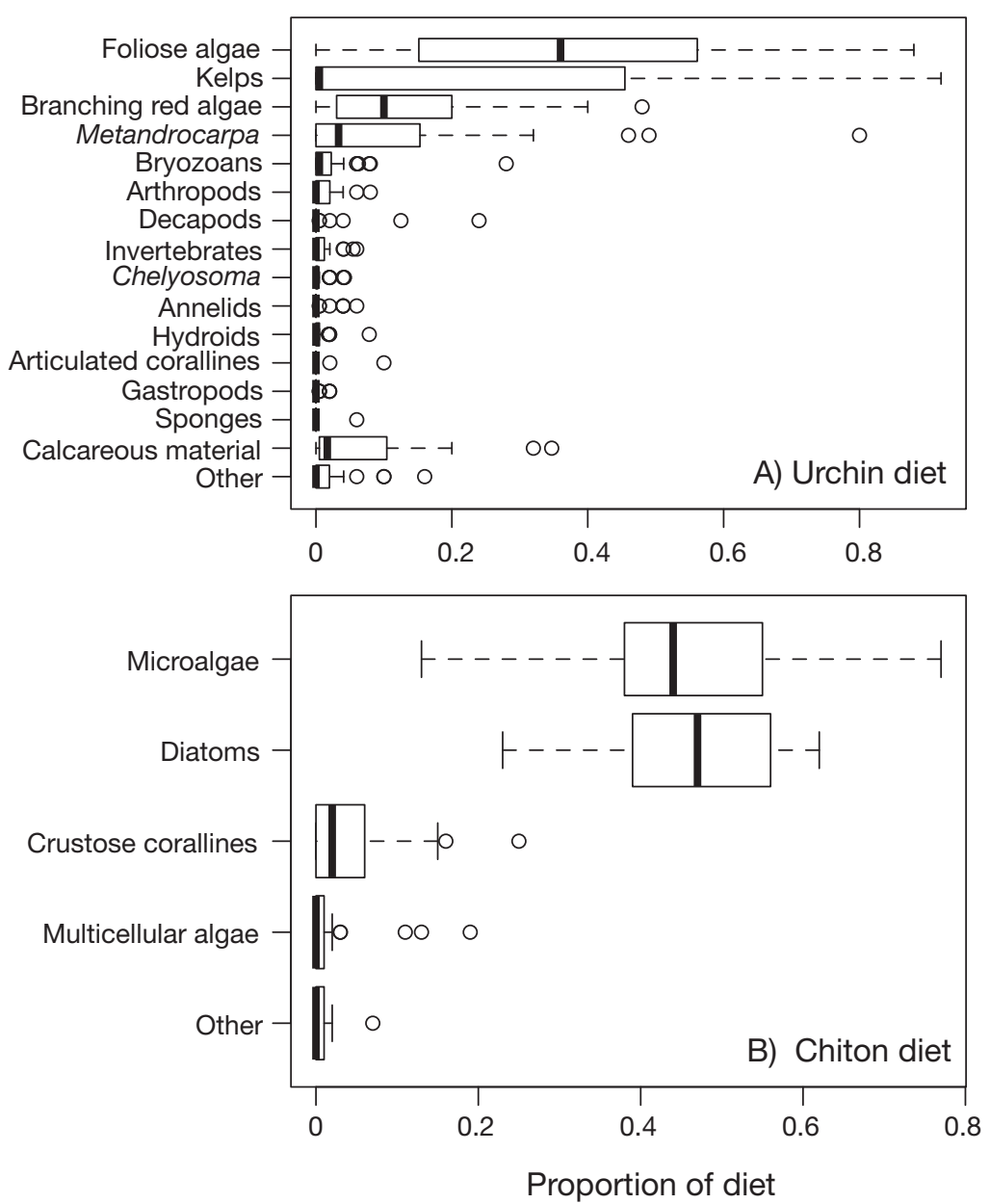

Fig. 5. (A) Macroalgae and a clonal ascidian, Metandrocarpa taylori, constitute the majority of the red urchin diet, whereas (B) microalgae and diatoms are the most abundant food items found in the intestines of Tonicella chitons. Chelyosoma is a solitary ascidian. Boxplots display the median and interquartile range (IQR) of data, with outliers plotted as circles beyond whiskers when the values are $1.5 \times$ IQR from the first or third quartile

anisms underlying dynamic variation between richness and available space use in epifaunal communities on natural substrata are critical to understanding the relevance of previous biodiversity-ecosystem function research in epifaunal communities on manmade structures (e.g. 'fouling' communities on docks). Given that we studied prey richness by observing natural gradients, it is surprising that its inverse relationship with available space was more concordant with experimental manipulations of sessile richness (Stachowicz et al. 1999, 2002) than with observational approaches in fouling communities. In contrast, available space increased with sessile diversity in unmanipulated, epifaunal dock assemblages, a consequence of high mortality rates of necessarily small colonies (Dunstan \& Johnson 2004). This mech- anism of size-specific mortality could become irrelevant in an artificially assembled community, yet our field observations support a negative relationship between richness and available space.

In addition to artificial assembly, we propose that grazing is another mechanism that negates the advantage that large invertebrate colonies possess in low-diversity, competitive arenas associated with relatively undisturbed habitats (e.g. docks; Dunstan \& Johnson 2004). Red urchins removed the spatial dominants (other than corallines and other crustose algae), though not necessarily the competitive dominants, such as large cnidarians, sponges and ascidians (Sebens 1986a,b). Urchins thus contributed to the variation in available space at low levels of prey richness (Figs. 1A \& 3). It is unclear whether urchins were selectively foraging for macroalgae (mostly red algae) and clonal ascidians, or whether they were simply consuming the most abundant prey available; red urchins are generally thought to prefer kelp (Vadas 1977). Regardless, in the absence of grazing disturbance, clonal ascidians and red algae are capable of monopolizing space on these rock walls, resulting in a triangular relationship (supported by quantile regression) between prey richness and available space. Both the survey and experimental data revealed that although there was an upper limit (significant upper quantile), there was no lower limit (nonsignificant lower quantile) to available space as a function of richness. In other words, quadrats with many $(>20)$ taxa had very little open space, but the amount of space was not necessarily high at low richness (Fig. 1). The absence of a lower limit is a consequence of the interaction between dominant space occupiers and the most abundant consumers.

The densities of 2 morphologically dissimilar consumers - urchins and chitons - together best explained patterns of available space in the surveys (Table 1). The positive correlation between consumer richness and open space (Fig. 1B) may have been related to the increased likelihood of including a chiton (Byrnes \& Stachowicz 2009), rather than a 'true' diversity effect (e.g. complementarity). Most importantly, the manipulation of urchins demonstrated 
Table 2. $\chi^{2}$ likelihood ratio tests and model selection results examining the fit of structural equation models (StEMs) to observed covariance matrices for survey and experimental data. We report Satorra-Bentler corrected $\chi^{2}$ test statistics, corrected AIC $\left(\mathrm{AIC}_{\mathrm{c}}\right)$, the difference in $\mathrm{AIC}$ between the candidate model and the best model $(\Delta i)$, and Akaike weights $\left(w_{\mathrm{i}}\right)$. StEM A: urchin facilitation, chiton grazing (saturated model); StEM B: no facilitation, chiton grazing; StEM C: urchin facilitation, no chiton grazing; StEM D: no facilitation, no chiton grazing. na: not applicable

\begin{tabular}{|c|c|c|c|c|c|c|}
\hline Model & df & $\chi^{2}$ & $\mathrm{p}$ & $\mathrm{AIC}_{\mathrm{c}}$ & $\Delta i$ & $W_{\mathrm{i}}$ \\
\hline \multicolumn{7}{|c|}{ Survey (2008) } \\
\hline StEM A & 0 & na & na & 1003.7 & 0.0 & 1.0 \\
\hline StEM B & 1 & 6.89 & 0.009 & 1018.2 & 14.5 & 0.0 \\
\hline StEM C & 2 & 13.57 & 0.001 & 1025.3 & 21.6 & 0.0 \\
\hline StEM D & 3 & 27.43 & $<0.001$ & 1039.9 & 36.2 & 0.0 \\
\hline \multicolumn{7}{|c|}{ Experiment (2009) } \\
\hline StEM A & 0 & na & na & 1340.7 & 0.0 & 1.0 \\
\hline StEM B & 1 & 11.21 & 0.001 & 1363.3 & 22.7 & 0.0 \\
\hline StEM C & 2 & 14.60 & 0.001 & 1365.1 & 24.4 & 0.0 \\
\hline StEM D & 3 & 36.44 & $<0.001$ & 1387.9 & 47.2 & 0.0 \\
\hline
\end{tabular}

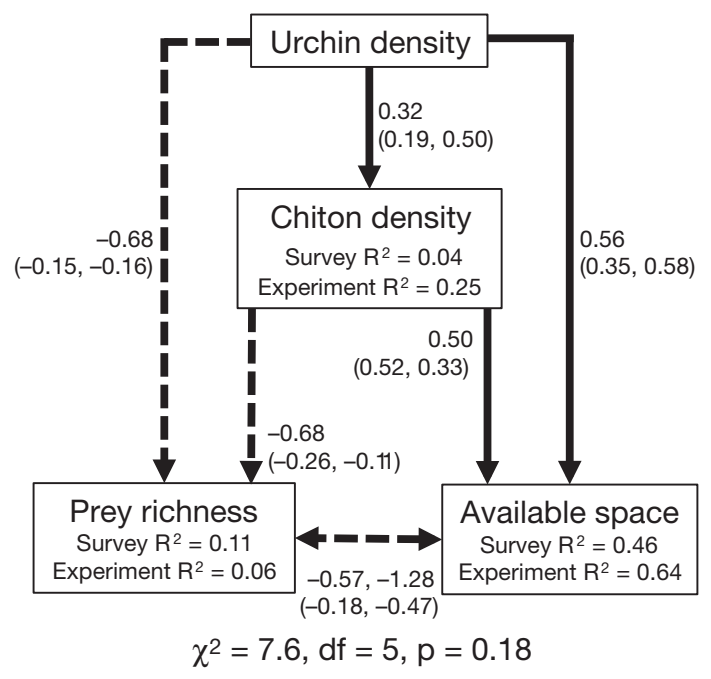

Fig. 6. Path diagram estimating the strength of direct and indirect effects of urchins. The covariance matrix of the combined survey and experimental data is adequately represented by a multi-group structural equation model with equality constraints for each of the 5 causal paths. Solid and dashed lines represent positive and negative relationships, respectively. All causal paths are significant ( $<<0.05)$; the number beside each path is the unstandardized path coefficient. Covariance between prey richness and available space was allowed to vary freely, and thus the 2 numbers below this path represent the unstandardized coefficients for the survey and experimental datasets, respectively. Likewise, the 2 numbers inside parentheses are the standardized coefficients for the survey and experimental datasets, respectively. The covariance between prey richness and available space was only significant for the experimental dataset mechanistically that they uncover new patches of available space on rock walls, accompanied by increases in chiton density and consumer richness (Fig. 2). Together, the survey and experimental data suggest that an instantaneous measure of free space, defined in this way, provides a snapshot of recent grazing disturbance (Sebens 1986b). It is likely that the density of chitons increased in response to urchin grazing because chitons cannot adhere effectively to the soft bodies of sessile invertebrates and thalli of red algae. Further, chiton diet was composed primarily of microalgae and diatoms (Fig. 5), which rapidly colonize encrusting algae and bare substrata (O'Neill \& Wilcox 1971, Dethier \& Duggins 1984). We hypothesize that the increase in consumer richness reflects a similar response, as we identified 4 species of Tonicella, 2 species of the chiton Mopalia, the chiton Lepidozona mertensii and several other mollusks (e.g. Margarites spp., Acmaea spp. and Lottia spp.) that may require encrusting algae as a suitable substratum for attachment and/or grazing (i.e. 'foraging space'; Dethier \& Duggins 1984). Our results indicate that red urchins, as generalist consumers of both macroalgae and sessile invertebrates, facilitate the diversity and abundance of chitons and other specialized consumers, in a manner similar to the 'indirect commensalism' observed between Katharina chitons and acmaeid limpets on intertidal rocky shores (Dethier \& Duggins 1984). In the latter study, small specialist limpets were dependent on the larger, generalist Katharina to remove macroalgae and provide the appropriate substratum for microalgal growth.

It is unlikely that urchins were solely responsible for the creation of available space, because StEMs lacking paths from chiton density to available space and prey richness fit the observed data poorly (Table 2). Furthermore, the effect of urchin grazing on the sessile community appears partially mediated through a facilitative effect on chitons, because incorporating a path from urchin density to chiton density greatly improved the fit of the model (StEM A; Table 2). Indeed, removing urchin facilitation (StEM B), chiton grazing (StEM C), or both (StEM D) resulted in poor model fit for both datasets (Table 2). Despite the inherent differences between the survey data (which integrate ecological effects over a longer time scale) and experimental data (which emphasize the top-down effects of a 3 mo 'pulse' disturbance) our multi-group analysis (Grace \& Pugesek 1998) suggests that the strength and direction of direct and indirect effects were similar across the 2 datasets. While the StEMs permit a richer ecological interpretation of our data than the 
linear mixed effects models alone, the role of chiton grazing as a causal mechanism must be viewed as a hypothesis to be tested in future manipulations (Wootton 1994).

The experimental treatment period coincided with summer recruitment in the San Juan Islands, thus the trend of increased richness on control transects in September (Fig. 2B) may have been manifested through chiton grazing on early life stages of sessile taxa (Nydam \& Stachowicz 2007). However, the effects of these 2 consumers on prey richness were relatively weak (Fig. 6), and grazing primarily affected the relative abundances of taxa (Fig. 2a). Any negative effects on prey richness would likely manifest only when red urchins occupy a specific area on rock walls for extended periods of time. In the San Juan Islands, we occasionally observe temporally stable (>5 yr), and dense $\left(\sim 18 \mathrm{~m}^{-2}\right)$, aggregations of red urchins on rock walls that are effectively barren, with few sessile species except for encrusting calcified algae (as in Sebens 1986b). Such prey-speciespoor walls are uncommon (R. Elahi pers. obs.), and may reflect a nonlinear threshold as described for kelp forest- urchin barren community shifts (Watanabe \& Harrold 1991, Arkema et al. 2009). The extent to which communities dominated by encrusting algae are maintained by the positive feedback of urchinmediated chiton grazing remains to be determined.

Although prey richness was independent of grazing at the end of the experiment, there was an interaction between urchin density and prey richness (Fig. 3), indicating that the upper bound of the relationship between available space and richness was related causally to the grazing effects of urchins. Similarly, the presence of upper trophic levels enhanced the effects of diversity on ecosystem function in seagrass (Duffy et al. 2005) and terrestrial plant (Parker et al. 2010) communities. Although red urchins ate a variety of prey, their diets were composed primarily of macroalgae and clonal ascidians (Fig. 5), and thus reflected the significant reductions in these 2 functional groups of sessile taxa after the experimental addition of urchins. The decline in cover of clonal ascidians (but not macroalgae) was consistent with the urchin-mediated variation in available space and prey richness. Namely, the significant median regression between clonal ascidian cover and prey richness after the addition of urchins appeared to be driven by disproportionately lower cover within quadrats harboring fewer taxa (Fig. 4B). In contrast, macroalgal cover was lower across all quadrats after urchin addition, regardless of prey richness, which may be related to urchin preference for algae.
The decline of spatially dominant prey was associated with an increase in prey evenness at the end of the experiment (Fig. 2C). Intermittent urchin grazing within the range of densities observed in this study may therefore act as a mechanism promoting coexistence of sessile taxa (Lubchenco 1978). In particular, solitary invertebrates suffer a clear disadvantage against clonal invertebrates with respect to competition for space (Jackson 1977). Urchins indirectly facilitated the significant increase in percent cover of solitary invertebrates (e.g. barnacles), probably by reducing the cover of clonal invertebrates (Fig. 2A). In addition to consuming clonal ascidians, urchins appear to have exerted negative effects on hydroid colonies, but these were probably not related to grazing (Fig. 5A). Perhaps non-trophic impacts, such as spine abrasion, prevented hydroids from increasing their percent cover on urchin addition transects (Fig. 2A).

In summary, our results indicate that urchin feeding on spatially dominant ascidians is one specific mechanism that drives variation in the triangular relationship between open space and richness. The availability of space is a useful metric of community structure (Paine 1984) and an important corollary of at least one ecosystem function: invasibility (Stachowicz et al. 2002, Clark \& Johnston 2011). The susceptibility of rocky shores to invasions of exotic sessile taxa at local scales $\left(<1 \mathrm{~m}^{2}\right)$ is likely a consequence of the indirect effects of grazing on resource availability and prey richness, in addition to the direct effects of biological disturbance (or lack thereof) on exotic species (Simoncini \& Miller 2007, Shinen et al. 2009, Grey 2010). Further, if we accept available space to be a reasonable index of recent grazing disturbance, the significant correlation between space and richness observed in the presence of urchins is consistent with the hypothesis that high prey richness buffers the impacts of grazing disturbance (Hillebrand \& Cardinale 2004, Edwards et al. 2010). Of course, correlations are always open to interpretation and we acknowledge the limitations of studying natural gradients in diversity. Even the static outcomes of ecological experiments may provide limited insight into the mechanisms of observed change (Wootton 1994). Our manipulation of urchins caused an increase in available space, but the role that chitons may play in the creation of space was not revealed until we applied a structural equation model to the data. A combination of approaches was necessary to uncover the potential for feedback among consumers and their prey. 
Acknowledgements. Many thanks to A. Dufault, T. Dwyer, E. Heery, K. Kull, K. Matterson, B. McCollum, A. Rhoades, $\mathrm{K}$. Turner and numerous volunteers for assistance in the field; and E. Haug, B. Hough, M. Rock and R. Whippo for assistance in the laboratory. This manuscript benefited from comments by J. Byrnes, J. Hille-Ris Lambers, M. Mach, S. Yang and 4 anonymous reviewers. Funding was provided by the ARCS (Achievement Rewards for College Scientists) foundation, Friday Harbor Laboratories, University of Washington Biology, the National Science Foundation (NSF) GK-12 (DGE 0742559) and NSF Biological Oceanography (OCE 0850809). This manuscript is in partial fulfillment of a PhD degree to R.E. from the Department of Biology at the University of Washington.

\section{LITERATURE CITED}

Arkema KK, Reed DC, Schroeter SC (2009) Direct and indirect effects of giant kelp determine benthic community structure and dynamics. Ecology 90:3126-3137

Bayen RH, Davidson DJ, Bates DM (2008) Mixed-effects modeling with crossed random effects for subects and items. J Mem Lang 59:390-412

Balvanera P, Pfisterer AB, Buchmann N, He J, Nakashizuka T, Raffaelli D, Schmid B (2006) Quantifying the evidence for biodiversity effects on ecosystem functioning and services. Ecol Lett 9:1146-1156

Bates DM, Maechler M, Bolker B (2011) lme4: Linear mixedeffects models using $\mathrm{S} 4$ classes. $\mathrm{R}$ package version 0.999375-42. R Foundation for Statistical Computing, Vienna. http://CRAN.R-project.org/package=lme4

> Bracken MES, Jones E, Williams SL (2011) Herbivores, tidal elevation, and species richness simultaneously mediate nitrate uptake by seaweed assemblages. Ecology 92: 1083-1093

- Breitburg DL (1984) Residual effects of grazing: inhibition of competitor recruitment by encrusting coralline algae. Ecology 65:1136-1143

Britton-Simmons KH, Foley G, Okamoto D (2009) Spatial subsidy in the subtidal zone: utilization of drift algae by a deep subtidal sea urchin. Aquat Biol 5:233-243

Burnham K, Anderson D (2002) Model selection and inference: a practical information theoretic approach. Springer Verlag, New York, NY

> Byrnes JE, Stachowicz JJ (2009) The consequences of consumer diversity loss: different answers from different experimental designs. Ecology 90:2879-2888

Byrnes JE, Reynolds PL, Stachowicz JJ (2007) Invasions and extinctions reshape coastal marine food webs. PLoS One 2:e295

Cade B, Noon B (2003) A gentle introduction to quantile regression for ecologists. Front Ecol Environ 1:412-420

Cardinale BJ, Palmer MA, Ives AR, Brooks SS (2005) Diversity-productivity relationships in streams vary as a function of the natural disturbance regime. Ecology 86: 716-726

> Carter SK, VanBlaricom GR, Allen BL (2007) Testing the generality of the trophic cascade paradigm for sea otters: a case study with kelp forests in northern Washington, USA. Hydrobiologia 579:233-249

Clark GF, Johnston EL (2011) Temporal change in the diversity-invasibility relationship in the presence of a disturbance regime. Ecol Lett 14:52-57

Cobb J, Lawrence JM (2005) Diets and coexistence of the sea urchins Lytechinus variegatus and Arbacia punctulata (Echinodermata) along the central Florida gulf coast. Mar Ecol Prog Ser 295:171-182

> Connell JH (1961) Effects of competition, predation by Thais lapillus, and other factors on natural populations of the barnacle Balanus balanoides. Ecol Monogr 31:61-104

> Connell JH (1978) Diversity in tropical rain forests and coral reefs. Science 199:1302-1310

> Dayton PK (1971) Competition, disturbance, and community organization: the provision and subsequent utilization of space in a rocky intertidal community. Ecol Monogr 41: 351-389

Demopulos PA (1975) Diet, activity and feeding in Tonicella lineata (Wood, 1815). Veliger 18S:42-46

> Dethier MN, Duggins DO (1984) An 'indirect commensalism' between marine herbivores and the importance of competitive hierarchies. Am Nat 124:205-219

> Dethier MN, Graham ES, Cohen S, Tear LM (1993) Visual versus random-point percent cover estimations: 'objective' is not always better. Mar Ecol Prog Ser 96:93-100

Duffy JE, Macdonald KS, Rhode JM, Parker JD (2001) Grazer diversity, functional redundancy, and productivity in seagrass beds: an experimental test. Ecology 82: 2417-2434

Duffy JE, Richardson JP, Canuel EA (2003) Grazer diversity effects on ecosystem functioning in seagrass beds. Ecol Lett 6:637-645

> Duffy JE, Richardson JP, France KE (2005) Ecosystem consequences of diversity depend on food chain length in estuarine vegetation. Ecol Lett 8:301-309

> Duggins DO (1980) Kelp beds and sea otters: an experimental approach. Ecology 61:447-453

> Duggins DO (1981) Sea urchins and kelp: the effects of short term changes in urchin diet. Limnol Oceanogr 26: 391-394

> Duggins DO, Dethier MN (1985) Experimental studies of herbivory and algal competition in a low intertidal habitat. Oecologia 67:183-191

Dunstan PK, Johnson CR (2004) Invasion rates increase with species richness in a marine epibenthic community by two mechanisms. Oecologia 138:285-292

- Edwards KF, Aquilino KM, Best RJ, Sellheim KL, Stachowicz JJ (2010) Prey diversity is associated with weaker consumer effects in a meta-analysis of benthic marine experiments. Ecol Lett 13:194-201

Epelbaum A, Pearce CM, Barker DJ, Paulson A, Therriault TW (2009) Susceptibility of non-indigenous ascidian species in British Columbia (Canada) to invertebrate predation. Mar Biol 156:1311-1320

Fulton FT (1975) The diet of the chiton Mopalia lignosa (Gould, 1846). Veliger 18S:38-41

Grace JB, Pugesek BH (1998) On the use of path analysis and related procedures for the investigation of ecological problems. Am Nat 152:151-159

- Grace JB, Anderson TM, Smith MD, Seabloom E and others (2007) Does species diversity limit productivity in natural grassland communities? Ecol Lett 10:680-689

Grace JB, Anderson TM, Olff H, Scheiner SM (2010) On the specification of structural equation models for ecological systems. Ecol Monogr 80:67-87

> Grey EK (2010) Effects of large enemies on success of exotic species in marine fouling communities of Washington, USA. Mar Ecol Prog Ser 411:89-100

Hillebrand H, Cardinale BJ (2004) Consumer effects decline with prey diversity. Ecol Lett 7:192-201 
Hooper DU, Chapin FS, Ewel JJ, Hector A and others (2005) Effects of biodiversity on ecosystem functioning: a consensus of current knowledge. Ecol Monogr 75:3-35

Jackson JBC (1977) Competition on marine hard substrata: the adaptive significance of solitary and colonial strategies. Am Nat 111:743-767

Koenker R (2011) quantreg: Quantile regression. R package version 4.78. $\mathrm{R}$ foundation for Statistical Computing, Vienna. http://CRAN.R-project.org/package=quantreg

> Latyshev NA, Khardin AS, Kasyanov SP, Ivanova MB (2004) A study on the feeding ecology of chitons using analysis of gut contents and fatty acid markers. J Molluscan Stud 70:225-230

Levine JM (2000) Species diversity and biological invasions: relating local process to community pattern. Science 288: 852-854

Lubchenco J (1978) Plant species diversity in a marine intertidal community: importance of herbivore food preference and algal competitive abilities. Am Nat 112:23-39

> MacArthur RH, Wilson EO (1963) An equilibrium theory of insular biogeography. Evolution 17:373-387

Miller RJ, Etter RJ (2011) Rock walls: small-scale diversity hotspots in the subtidal Gulf of Maine. Mar Ecol Prog Ser 425:153-165

> Morse DE, Hooker N, Morse ANC, Jensen RA (1988) Control of larval metamorphosis and recruitment in sympatric agariciid corals. J Exp Mar Biol Ecol 116: 193-217

Nydam M, Stachowicz JJ (2007) Predator effects on fouling community development. Mar Ecol Prog Ser 337:93-101

O'Neill TB, Wilcox GL (1971) The formation of a 'primary film' on materials submerged in the sea at Port Hueneme, California. Pac Sci 25:1-12

Paine RT (1966) Food web complexity and species diversity. Am Nat 100:65-75

Paine RT (1984) Ecological determinism in the competition for space. Ecology 65:1339-1348

Paine RT (1992) Food-web analysis through field measurement of per capita interaction strength. Science 355: 73-75

- Paine RT (2002) Trophic control of production in a rocky intertidal community. Science 296:736-739

Paine RT, Vadas RL (1969) Effects of grazing by sea urchins, Strongylocentrototus spp., on benthic algal populations. Limnol Oceanogr 14:710-719

Parker JD, Salminen J, Agrawal AA (2010) Herbivory enhances positive effects of plant genotypic diversity. Ecol Lett 13:553-563

R Development Core Team (2011) R: A language and environment for statistical computing. R Foundation for Statistical Computing, Vienna

Robb MF (1975) The diet of the chiton Cyanoplax hartwegii in three intertidal habitats. Veliger 18S:34-37

Rosseel Y, Oberski D, Byrnes JE (2011) lavaan: Latent variable analysis. $\mathrm{R}$ package version $0.4-12$. R foundation for Statistical Computing, Vienna. http://CRAN.R-project. org/package=lavaan

Scharf FS, Juanes F, Sutherland M (1998) Inferring ecological relationships from the edges of scatter diagrams: comparison of regression techniques. Ecology 79: 448-460

Sebens KP (1986a) Spatial relationships among encrusting

Editorial responsibility: Antony Underwood,

Sydney, New South Wales, Australia marine organisms in the New England subtidal zone. Ecol Monogr 56:73-96

Sebens KP (1986b) Community ecology of vertical rock walls in the Gulf of Maine, USA: small-scale processes and alternative community states. In: Moore P, Seed R (eds) The ecology of rocky coasts. Columbia University Press, New York, NY, p 298-328

Shinen JS, Morgan SG, Chan AL (2009) Invasion resistance on rocky shores: direct and indirect effects of three native predators on an exotic and a native prey species. Mar Ecol Prog Ser 378:47-54

Simoncini M, Miller RJ (2007) Feeding preference of Strongylocentrotus droebachiensis (Echinoidea) for a dominant native ascidian, Aplidium glabrum, relative to the native ascidian Botrylloides violaceus. J Exp Mar Biol Ecol 342:93-98

Spooner DE, Vaughn CC (2009) Species richness and temperature influence mussel biomass: a partitioning approach applied to natural communities. Ecology 90: 781-790

Stachowicz JJ, Byrnes JE (2006) Species diversity, invasion success, and ecosystem functioning: disentangling the influence of resource competition, facilitation, and extrinsic factors. Mar Ecol Prog Ser 311:251-262

Stachowicz JJ, Whitlach RB, Osman RW (1999) Species diversity and invasion resistance in a marine ecosystem. Science 286:1577-1579

> Stachowicz JJ, Fried H, Osman RW, Whitlach RB (2002) Biodiversity, invasion resistance, and marine ecosystem function: reconciling pattern and process. Ecology 83: 2575-2590

Stachowicz JJ, Bruno JF, Duffy JE (2007) Understanding the effects of marine biodiversity on communities and ecosystems. Annu Rev Ecol Syst 38:739-766

> Stachowicz JJ, Best RJ, Bracken MES, Graham MH (2008) Complementarity in marine biodiversity manipulations: reconciling divergent evidence from field and mesocosm experiments. Proc Natl Acad Sci USA 105:18842-18847

Underwood AJ, Denley EJ, Moran MJ (1983) Experimental analyses of the structure and dynamics of mid-shore rocky intertidal communities in New South Wales. Oecologia 56:202-219

Vadas RL (1977) Preferential feeding: an optimization strategy in sea urchins. Ecol Monogr 47:337-371

> Vance RR (1988) Ecological succession and the climax community on a marine subtidal rock wall. Mar Ecol Prog Ser 48:125-136

> Watanabe JM, Harrold C (1991) Destructive grazing by sea urchins Strongylocentrotus spp. in a central California kelp forest: potential roles of recruitment, depth, and predation. Mar Ecol Prog Ser 71:125-141

Witman JD, Dayton PK (2001) Rocky subtidal communities. In: Bertness MD, Gaines SD, Hay ME (eds) Marine community ecology. Sinauer Associates, Sunderland, MA, p 229-366

> Witman JD, Etter RJ, Smith F (2004) The relationship between regional and local species diversity in marine benthic communities: a global perspective. Proc Natl Acad Sci USA 101:15664-15669

> Wootton JT (1994) Predicting direct and indirect effects: an integrated approach using experiments and path analysis. Ecology 75:151-165

Submitted: August 15, 2011; Accepted: January 13, 2012 Proofs received from author(s): April 8, 2012 